\title{
ChemComm
}

\section{Intramolecular $\mathrm{N}-\mathrm{H} \ldots \mathrm{Cl}$ hydrogen bonds in the outer coordination sphere of a bipyridyl bisurea-based ligand stabilize a tetrahedral $\mathrm{FeLCl}_{2}$ complex†}

Cite this: Chem. Commun., 2014 50, 7173

Received 28th March 2014, Accepted 14th May 2014

DOI: $10.1039 /$ c4cc02297a

www.rsc.org/chemcomm

\author{
Jesse V. Gavette, ${ }^{a}$ Christina M. Klug, ${ }^{b}$ Lev N. Zakharov, ${ }^{c}$ Matthew P. Shores, ${ }^{\star b}$ \\ Michael M. Haley*a and Darren W. Johnson*a
}

\begin{abstract}
A bipyridyl-based anion receptor is utilized as a ligand in a tetrahedral $\mathrm{FeCl}_{2}$ complex and demonstrates secondary coordination sphere influence through intramolecular hydrogen bonding to the chloride ligands as evidenced by X-ray crystallography.
\end{abstract}

Ligands capable of metal coordination while simultaneously hydrogen bonding to anionic guests have drawn considerable interest. ${ }^{1-4}$ Perhaps due to the ubiquity of iron and its relevance in biological systems, numerous coordination complexes designed as "hosts" for anions feature iron in their binding site. Some of these systems have utilized intramolecular hydrogen bonding to mimic the subtle secondary coordination sphere influences found in metalloproteins. ${ }^{5,6}$ Intermolecular hydrogen bonding systems have also been used to allow secondary coordination of anions to modulate the spin states of metal complexes for potential applications in data storage and sensing. ${ }^{7-11}$ In light of these emerging applications and the inherent challenge in targeting coordination of a metal complex rather than just a single metal ion, the design of novel ligands that coordinate metal complexes through both direct chelation and hydrogen bonding, remains an active area of ion coordination chemistry.

Recently we reported anion binding studies of bipyridyl bisurea-based receptor 1 (Fig. 1). ${ }^{12}$ This receptor displayed a particular affinity toward the dihydrogen phosphate anion, $\mathrm{H}_{2} \mathrm{PO}_{4}{ }^{-}$, in $10 \%$ DMSO-chloroform-based solvent mixtures. The ditopic binding environment of this receptor, which provides two urea groups for convergent hydrogen bonding to stabilize negative

\footnotetext{
${ }^{a}$ Department of Chemistry \& Biochemistry and Materials Science Institute, University of Oregon, Eugene, OR 97403-1253, USA. E-mail: dwj@uoregon.edu, haley@uoregon.edu; Tel: +1-541-346-1253, +1-541-346-0456

${ }^{b}$ Department of Chemistry, Colorado State University, Fort Collins, CO 80523-1872, USA. E-mail: matthew.shores@colostate.edu; Tel: +1-970-491-7235 ${ }^{C}$ CAMCOR-Center for Advanced Materials Characterization in Oregon, University of Oregon, Eugene, OR 97403-1253, USA

$\dagger$ Electronic supplementary information (ESI) available: Experimental and magnetic measurements, X-ray analysis of receptor. CCDC 978233. For ESI and crystallographic data in CIF or other electronic format see DOI: 10.1039/ c4cc02297a
}

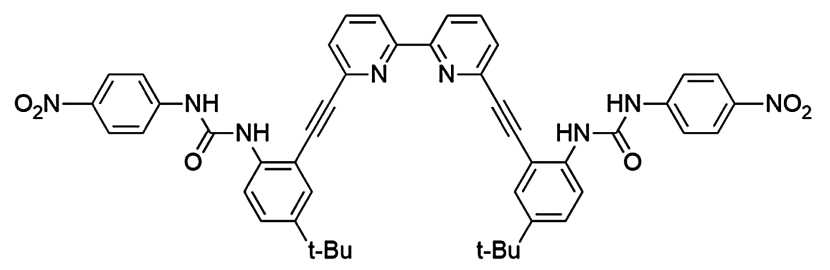

Fig. 1 Structural representation of 1.

charges and bipyridyl nitrogen lone-pairs for stabilizing positive charges, was the source of the preference toward this diprotic oxoanion. Based on this receptor design, it was recognized that the binding pocket should be suitable to a variety of guests possessing either (or both) positive and negative charges. Given the ubiquity of bipyridine as a ligand for transition metals, we were interested in investigating if the hydrogen bond donor groups on 1 would act in tandem with the bipyridyl group to coordinate and hydrogen bond to small metal complexes. Such molecular recognition of metal complexes has been termed "stereognostic" coordination chemistry. ${ }^{13}$

Herein we report solid state X-ray analysis and SQUID studies of the coordination of 1 with $\mathrm{FeCl}_{2}$, indicating the formation of a tetrahedral 1 $\cdot \mathrm{FeCl}_{2}$ metal complex. Surprisingly, this species features four tight intramolecular hydrogen bonding interactions between the two urea groups and the coordinated chloride ligands remaining on the $\mathrm{Fe}^{2+}$ metal centre.

Slow evaporation of 1 with excess $\mathrm{FeCl}_{2} \cdot 4 \mathrm{H}_{2} \mathrm{O}$ in acetonitrile resulted in yellow block-shaped crystals. ${ }^{14}$ The subsequent X-ray structure shows an $\mathrm{Fe}^{2+}$ ion coordinated in a tetrahedral geometry by two chlorides and the bipyridyl core; the binding is likely reinforced by the interaction between the two urea "arms" of the ligand and the metal-bound chloride ligands (Fig. 2a). The urea $\mathrm{N}-\mathrm{Cl}$ bond distances and $\mathrm{N}-\mathrm{H} \cdots \mathrm{Cl}$ bond angles indicate the formation of two moderate to weak hydrogen bonds ${ }^{15}$ to each of the coordinated chloride ligands by the respective urea functional groups (Table 1). Examples of this type of intramolecular hydrogen bonding to metal halides in the solid state are limited, and are typified by hydrogen bonding to a single halide ligand. ${ }^{16-19}$ 


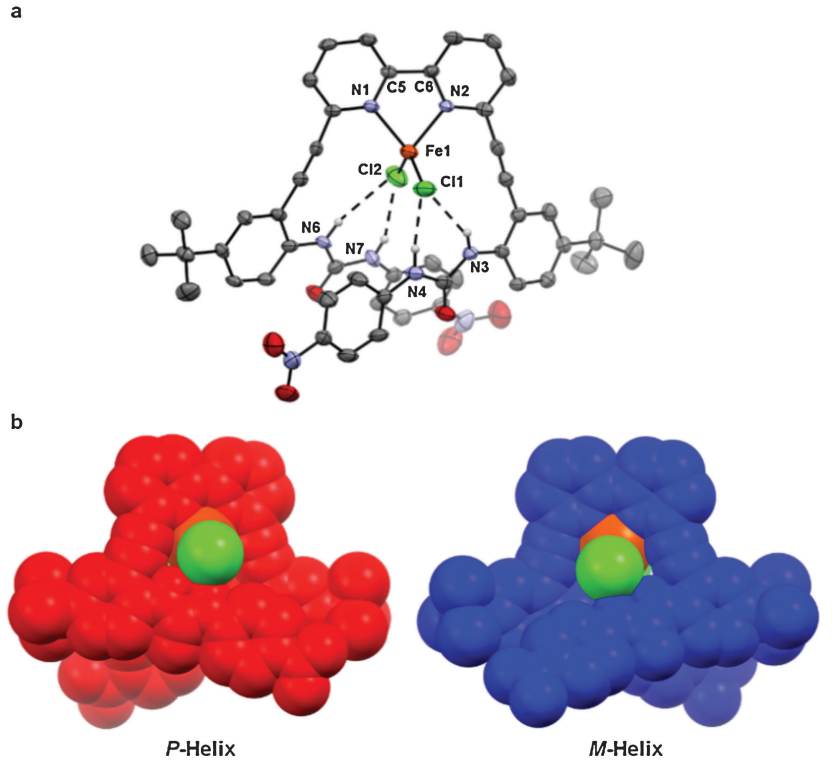

Fig. 2 X-Ray data of 1 represented as (a) an ORTEP structure (ellipsoids at $50 \%$ probability and non-coordinating hydrogens removed for clarity) and (b) space filling structures of both $P$ and $M$ helices.

Table 1 Selected bond distances $(\AA)$ and angles $\left({ }^{\circ}\right)$ of $1 \cdot \mathrm{FeCl}_{2}$

\begin{tabular}{|c|c|c|}
\hline Bond & Distance & Angle \\
\hline Fe1-N1 & $2.030(5)$ & - \\
\hline Fe1-N2 & $2.066(5)$ & - \\
\hline Fe1-Cl1 & $2.188(3)$ & - \\
\hline $\mathrm{Fe} 1-\mathrm{Cl} 2$ & $2.201(3)$ & - \\
\hline N3 $\cdots$ Cl1 & $3.407(6)$ & $151^{a}$ \\
\hline $\mathrm{N} 4 \cdots \mathrm{Cl} 1$ & $3.096(7)$ & $156^{a}$ \\
\hline $\mathrm{N} 6 \cdots \mathrm{Cl} 2$ & $3.581(6)$ & $152^{a}$ \\
\hline $\mathrm{N} 7 \cdots \mathrm{Cl} 2$ & $3.190(6)$ & $171^{a}$ \\
\hline N1-Fe1-N2 & - & 79.6(2) \\
\hline Cl1-Fe1-Cl2 & - & $122.06(10)$ \\
\hline N1-Fe1-Cl1 & - & $112.23(17)$ \\
\hline N2-Fe1-Cl1 & - & $110.64(18)$ \\
\hline $\mathrm{N} 1-\mathrm{Fe} 1-\mathrm{Cl} 2$ & - & $108.94(17)$ \\
\hline N2-Fe1-Cl2 & - & $115.45(16)$ \\
\hline
\end{tabular}

The observation that this structure allows the formation of up to four intramolecular hydrogen bonds to the two coordinated halides on the metal highlights the novelty of the presented ligand design. Curiously, the average $\mathrm{Fe}-\mathrm{N}$ and $\mathrm{Fe}-\mathrm{Cl}$ distances of $1 \cdot \mathrm{FeCl}_{2}(2.048(5) \AA$ and $2.194(8) \AA$, respectively) are shorter on average than those of similarly structured biheteroarylcoordinated tetrahedral $\mathrm{FeCl}_{2}$ complexes (with average distances

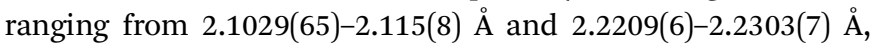
respectively). ${ }^{20-22}$ This may be a result of the ligand constricting the metal salt within the binding pocket. Additionally, the crystal structure reveals that the convergent coordination of the ureabased ligand appendages results in a helical twist in the binding conformation, and both enantiomers ( $P$ and $M$ helices, Fig. 2 b) are present in a racemic mixture in the solid state. Such guestinduced helical chirality has received much attention recently, ${ }^{23-25}$ and represents an interesting area of further research for this and related systems.
In an effort to characterize the iron complex in solution, determination of the magnetic susceptibility $\left(\gamma_{M}\right)$ by ${ }^{1} \mathrm{H}$ NMR using Evans method ${ }^{26,27}$ was attempted. The low solubility of ligand 1 and of the resultant 1. $\mathrm{FeCl}_{2}$ complex in common organic solvents dictated the use of highly coordinating solvents $\left(e . g\right.$. DMSO- $\left.d_{6}\right)$ to achieve appreciable concentrations of the $\mathrm{Fe}^{2+}$ species in a 90:10 $\mathrm{CDCl}_{3}$ : DMSO- $d_{6}$ solution. The limited solubility and temperature range available in this solvent system lead to ${ }^{1} \mathrm{H}$ NMR spectra of the metal complex that suffered from problems ranging from extreme peak broadening to spectra that were nearly identical to that of the free ligand. This prevented the collection of reliable magnetic susceptibility measurement values in solution. These observations are consistent with the dissociation of the metal salt and ligand in highly polar (competitive) solvents. The complex was also not stable under ESI-MS conditions, and dissociated iron species and free ligand represent the major ions observed, although small amounts of ligated Fe-complexes were observed (see Fig. S3 and S4, ESI†). The apparent dissociation in solution is likely perpetuated by a frustrated coordination environment indicated by the short Fe-N and $\mathrm{Fe}-\mathrm{Cl}$ bond distances observed in the solid state.

Although virtually all tetrahedral $\mathrm{Fe}^{2+}$ complexes are high spin, the short $\mathrm{Fe}-\mathrm{N}$ and $\mathrm{Fe}-\mathrm{Cl}$ bond distances observed in $\mathbf{1} \cdot \mathrm{FeCl}_{2}$ imply that the compound is close to the spin crossover regime. In the solid state, magnetic susceptibility measurements of $\mathbf{1} \cdot \mathrm{FeCl}_{2}$ show a high spin $\mathrm{Fe}^{2+}(S=2)$ species at $295 \mathrm{~K}$ with a $\chi_{\mathrm{M}} T$ value of $3.78 \mathrm{emu} \mathrm{K} \mathrm{mol}^{-1}\left(\mu_{\mathrm{eff}}=5.5\right)$ (Fig. 3). This value is consistent with other reported high-spin tetrahedral $\mathrm{Fe}^{2+}$ complexes, ${ }^{20,22,28}$ supporting the tetrahedral structure observed by X-ray analysis. At lower temperatures, a slight decrease in susceptibility is observed, dropping to $3.15 \mathrm{emu} \mathrm{K} \mathrm{mol}^{-1}\left(\mu_{\mathrm{eff}}=5.0\right)$ at $15 \mathrm{~K}$, with a more drastic decrease in the $\chi_{\mathrm{M}} T$ value at $5 \mathrm{~K}$. This downturn is consistent with zero-field splitting of the high-spin $\mathrm{Fe}^{2+}$ ion due to the low symmetry ligand field.

Coordination of bipyridyl-based ligands with steric bulk adjacent to the donor atom tends to allow spin crossover for octahedral $\mathrm{Fe}^{2+}$ complexes; ${ }^{29}$ otherwise, aromatic diimines generally lead

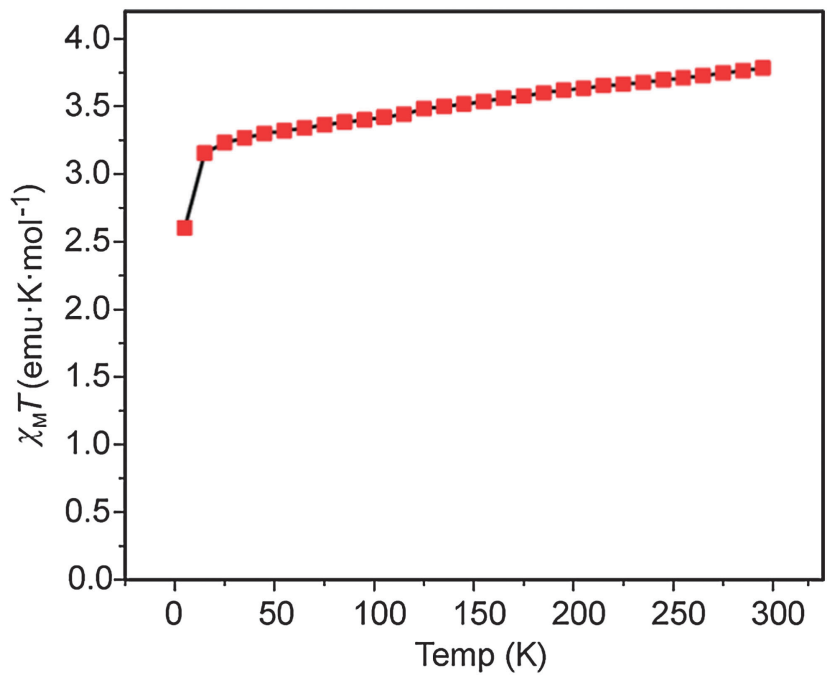

Fig. 3 Temperature dependence of $\chi_{M} T$ for $1 . \mathrm{FeCl}_{2}$, obtained under a 1000 Oe measuring field. Line added only as a guide for the eye. 
to low-spin species. Meanwhile, chloride is a weak field ligand and often leads to high spin $\mathrm{Fe}^{2+}$ complexes. Since the $\mathrm{Fe}^{2+}$ ion in 1. $\mathrm{FeCl}_{2}$ is in a tetrahedral coordination environment, thermally accessible spin crossover would require that the ligand field imparted by $\mathbf{1}$ and two $\mathrm{Cl}^{-}$anions be significantly stronger than what the combination of bipyridyl and chloride typically generate in hexacoordinate complexes. This ligand field argument is consistent with the data shown in Fig. 3.

Another consideration is structural rigidity. The one tetrahedral $\mathrm{Fe}^{2+}$ species which undergoes spin crossover, $\left[\mathrm{PhB}(\mathrm{MesIm})_{3} \mathrm{Fe}-\mathrm{NdPPh}_{3}\right]$, has a more flexible ligand set imparted by a tris(carbene)borate and axial phosphoraniaminato ligands. ${ }^{30}$ These moieties allow for the proper ligand distortions necessary to observe spin state changes. For $\mathbf{1} \cdot \mathrm{FeCl}_{2}$, we postulate these distortions are not favored due to the rigidity of the bipyridyl and the intramolecular hydrogen-bonding network. Thus, the complex remains trapped in the high-spin state even though the Fe-N bond lengths suggest that the low-spin state should be accessible.

In conclusion, we have demonstrated that a bipyridyl bisureabased receptor designed to ditopically coordinate protic anions provides a suitable framework as a ligand toward metal halide salts. Solid state investigation of the $\mathrm{Fe}^{2+}$ complex reveals the presence of intramolecular hydrogen bonds between $\mathbf{1}$ and the metal-coordinated halide ligands. These findings demonstrate the potential of this and related systems ${ }^{31-35}$ to affect coordinated metal centres through non-covalent interactions. Additionally, the helical nature of the formed ligand complex presented offers a potential avenue for incorporating enantiospecific recognition into future generations of ligand design.

This work was supported by NIH grant R01-GM087398, which also funded early stage intellectual property that was licensed by SupraSensor Technologies, a company co-founded by D.W.J and M.M.H. M.P.S. and C.M.K. thank the NSF (CHE-1058889) and Colorado State University for support of this work.

\section{Notes and references}

1 V. Amendola and L. Fabbrizzi, Chem. Commun., 2009, 513-531.

2 J. W. Steed, Chem. Soc. Rev., 2009, 38, 506-519.

3 D. J. Mercer and S. J. Loeb, Chem. Soc. Rev., 2010, 39, 3612-3620.

4 J. Pérez and L. Riera, Chem. Soc. Rev., 2008, 37, 2658-2667.

5 (a) A. S. Borovik, Acc. Chem. Res., 2005, 38, 54-61; (b) C. E. MacBeth, A. P. Golombek, V. G. Young, Jr., C. Yang, K. Kuczera, M. P. Hendrich and A. S. Borovik, Science, 2000, 289, 938-941.

6 (a) T. M. Dewey, J. Du Bois and K. N. Raymond, Inorg. Chem., 1993, 32, 1729-1738; (b) A. S. Borovik, J. Du Bois and K. N. Raymond, Angew. Chem., Int. Ed. Engl., 1995, 34, 1359-1362; (c) T. S. Franczyk, K. R. Czerwinski and K. N. Raymond, J. Am. Chem. Soc., 1992, 114, 8138-8146.

7 Z. Ni, A. M. McDaniel and M. P. Shores, Chem. Sci., 2010, 1, 615-621.
8 C. M. Klug, A. M. McDaniel, S. R. Fiedler, K. A. Schulte, B. S. Newell and M. P. Shores, Dalton Trans., 2012, 41, 12577-12585.

9 Z. Ni and M. P. Shores, J. Am. Chem. Soc., 2009, 131, 32-33.

10 G. Lemercier, N. Bréfuel, S. Shova, J. A. Wolny, F. Dahan, M. Verelst, H. Paulsen, A. X. Trautwein and J.-P. Tuchagues, Chem. - Eur. J., 2006, 12, 7421-7432.

11 H. Z. Lazar, T. Forestier, S. A. Barrett, C. A. Kilner, J.-F. Létard and M. A. Halcrow, Dalton Trans., 2007, 4276.

12 J. V. Gavette, N. S. Mills, L. N. Zakharov, C. A. Johnson, D. W. Johnson and M. M. Haley, Angew. Chem., Int. Ed., 2013, 52, 10270-10274.

13 T. S. Franczyk, K. R. Czerwinski and K. N. Raymond, J. Am. Chem. Soc., 1992, 114, 8138-8146.

14 Crystallographic data for 1. $\mathrm{FeCl}_{2}(\mathrm{CCDC} 978233): \mathrm{C}_{48} \mathrm{H}_{42} \mathrm{Cl}_{2} \mathrm{FeN}_{8} \mathrm{O}_{6}$, $M=953.65,0.12 \times 0.07 \times 0.05 \mathrm{~mm}, T=173(2) \mathrm{K}$, triclinic, space group $P \overline{1}, a=11.666(9) \AA, b=11.764(9) \AA ⿻$ $, c=18.282(14) \AA, \alpha=$ 78.585(16) ${ }^{\circ}, \beta=88.896(19)^{\circ}, \gamma=63.247(16)^{\circ}, V=2189(3) \AA^{3}, Z=2$, $D_{\mathrm{c}}=1.447 \mathrm{Mg} \mathrm{m}^{-3}, \mu=0.528 \mathrm{~mm}^{-1}, F(000)=988,2 \theta_{\max }=50.00^{\circ}$, 17504 reflections, 7664 independent reflections $\left[R_{\text {int }}=0.0971\right]$, $R_{1}=0.0838, \mathrm{w} R_{2}=0.1879$ and $\mathrm{GOF}=1.006$ for 7664 reflections (586 parameters) with $I>2 \sigma(I), R_{1}=0.1693, \mathrm{w} R_{2}=0.2368$ and $\mathrm{GOF}=1.006$ for all reflections, $\mathrm{max} / \mathrm{min}$ residual electron density $+1.126 /-0.610$ e $\AA^{3}$.

15 J. W. Steed and J. L. Atwood, Supramolecular Chemistry, John Wiley and Sons, 2nd edn, 2009.

16 T. E. Patten, C. Troeltzsch and M. M. Olmstead, Inorg. Chem., 2005, 44, 9197-9206.

17 D. Petrovic, M. Tamm and E. Herdtweck, Acta Crystallogr., Sect. C: Cryst. Struct. Commun., 2006, 62, m217-m219.

18 C. M. Moore and N. K. Szymczak, Chem. Commun., 2013, 49, 400.

19 C. M. Moore, D. A. Quist, J. W. Kampf and N. K. Szymczak, Inorg. Chem., 2014, 53, 3278-3280.

20 B. C. K. Chan and M. C. Baird, Inorg. Chim. Acta, 2004, 357, $2776-2782$

21 N. Rahimi, N. Safari, V. Amani and H. R. Khavasi, Acta Crystallogr., Sect. E: Struct. Rep. Online, 2009, 65, m1370.

22 O. Das, S. Chatterjee and T. K. Paine, JBIC, J. Biol. Inorg. Chem., 2013, 18, 401-410.

23 H. Miyake and H. Tsukube, Chem. Soc. Rev., 2012, 41, 6977-6991.

24 H. Juwarker, J. Suk and K.-S. Jeong, Chem. Soc. Rev., 2009, 38, 3316-3325.

25 P. Prabhakaran, G. Priya and G. J. Sanjayan, Angew. Chem., Int. Ed., 2012, 51, 4006-4008.

26 D. F. Evans, J. Chem. Soc., 1959, 2003-2005.

27 E. M. Schubert, J. Chem. Educ., 1992, 69, 62.

28 J. R. Hall, M. R. Litzow and R. A. Plowman, Aust. J. Chem., 1966, 19, 201-206.

29 Spin Crossover in Transition Metal Compounds I, ed. P. Gütlich and H. A. Goodwin, Springer, Berlin, Heidelberg, 2004, vol. 233.

30 J. J. Scepaniak, T. D. Harris, C. S. Vogel, J. Sutter, K. Meyer and J. M. Smith, J. Am. Chem. Soc., 2011, 133, 3824-3827.

31 C. A. Johnson, O. B. Berryman, A. C. Sather, L. N. Zakharov, M. M. Haley and D. W. Johnson, Cryst. Growth Des., 2009, 9, 4247-4249.

32 C. N. Carroll, B. A. Coombs, S. P. McClintock, C. A. Johnson II, O. B. Berryman, D. W. Johnson and M. M. Haley, Chem. Commun., 2011, 47, 5539-5541.

33 C. N. Carroll, O. B. Berryman, C. A. Johnson, L. N. Zakharov, M. M. Haley and D. W. Johnson, Chem. Commun., 2009, 2520-2522.

34 M. M. Watt, L. N. Zakharov, M. M. Haley and D. W. Johnson, Angew. Chem., Int. Ed., 2013, 52, 10275-10280.

35 O. B. Berryman, C. A. Johnson, L. N. Zakharov, M. M. Haley and D. W. Johnson, Angew. Chem., Int. Ed., 2008, 47, 117-120. 